\title{
Benzimidazole scaffolds as promising antiproliferative agents: a review
}

\author{
Sumit Tahlan, Sanjiv Kumar, Saloni Kakkar and Balasubramanian Narasimhan* (1)
}

\begin{abstract}
Cancer is one of the most serious medical problem and second leading cause of death in the world, characterized by a deregulation of the cell cycle which mainly results in a progressive loss of cellular differentiation and uncontrolled cellular growth. The benzimidazole is a heterocyclic moiety found in extensive number of natural and biological active molecules. Benzimidazole derivatives might be considered as auxiliary isosters of nucleotides having attached heterocyclic cores in their structures, cooperate effortlessly with biopolymers and have potential action for chemotherapeutic applications. Benzimidazole and its derivatives displayed a wide range of biological activity because of its structural similarity with the naturally occurring nucleotides. Benzimidazole has established huge alertness in current time and is extremely significant heterocyclic pharmacophore in recent drug innovation and medicinal chemistry. The present review summarizes the chemistry of various substituted benzimidazole derivatives with their antiproliferative significance towards the various cancer cell lines such as HCT116, MCF7, HeLa, HepG2, A549 and A431.
\end{abstract}

Keywords: Benzimidazole derivatives, Anticancer activity, MTT assay, SRB assay

\section{Introduction}

Cancer is one of the most serious medical problem and second leading cause of death in the world, characterized by a deregulation of the cell cycle which mainly results in a progressive loss of cellular differentiation and uncontrolled cellular growth. Hence there is a need to develop those agents whose chemical characteristics clearly differ from those existing agents and can overcome the problem of resistance. In present situation, the most engaged and demanding undertaking is the design, synthesis and development of new biologically active heterocycle compounds. Heterocyclic entities act as medications since they have precise synthetic reactivity and they give advantageous site to which bioactive substituents can be bind. Subsequently, there is need for the improvement of pharmacologically active heterocycles in synthetic and therapeutic science with certain focal points including its effortlessness of activity, greener methodology, simple workup strategy, selectivity, higher yields and high-particle monetary $[1,2]$.

\footnotetext{
*Correspondence: naru2000us@yahoo.com

Faculty of Pharmaceutical Sciences, Maharshi Dayanand University,

Rohtak 124001, India
}

In the medicinal field, the utility of heterocyclic entities has been raising each day because of structural similarities with biological molecules like nutrients, antibiotics. In spite of the fact that it including almost one-fourth of best hundred offering drugs yet because of issues like obstruction, poisonous quality, there is a requirement for minor change in existing drug molecules and to structure novel molecules which fuse benzimidazole as pharmacophore which are active against new targets [3]. Substituted benzimidazole might be a vital pharmacophore in bioactive agent innovation. Recently, noticeably consideration has been given to the design and synthesis of substituted benzimidazoles. Current perceptions advocate that substituted benzimidazoles and heterocycles demonstrate interface with the biopolymers, have potential action with lower toxicities. The substituted benzimidazoles are helpful for the improvement of ongoing scaffolds of pharmaceutical or natural concern [4].

Benzimidazole is also named as 3 -azaindole, azindole, benziminazole, benzoglyoxaline, 3-benzodiazole, 1,3-diazaindene having melting point of $170-172{ }^{\circ} \mathrm{C}$ and occurs as white crystals [5]. Benzimidazole is an important structural motif found in extensive number of natural and pharmacologically active molecules. Especially,

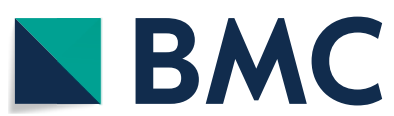

(c) The Author(s) 2019. This article is distributed under the terms of the Creative Commons Attribution 4.0 International License (http://creativecommons.org/licenses/by/4.0/), which permits unrestricted use, distribution, and reproduction in any medium, provided you give appropriate credit to the original author(s) and the source, provide a link to the Creative Commons license, and indicate if changes were made. The Creative Commons Public Domain Dedication waiver (http://creativecommons.org/ publicdomain/zero/1.0/) applies to the data made available in this article, unless otherwise stated. 


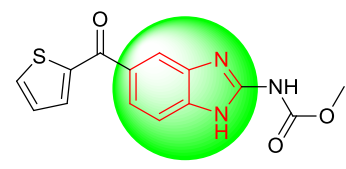

(i)

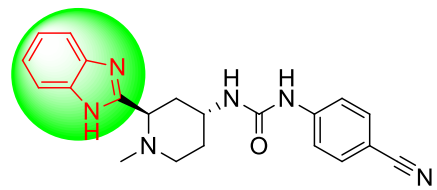

(iv)

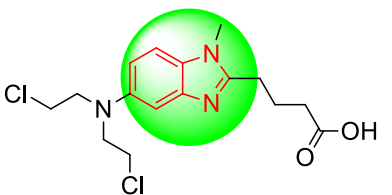

(ii)

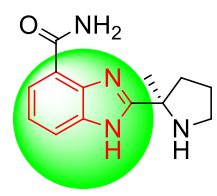

(iii)

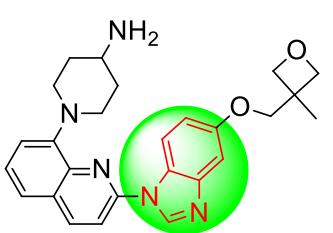

(v)

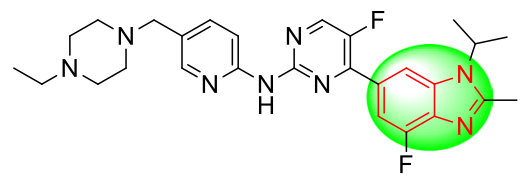

(vi)

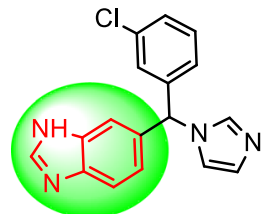

(vii)

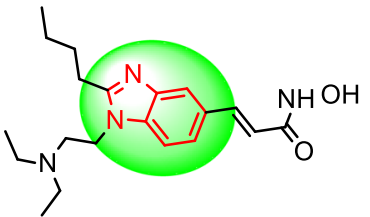

(viii)

Fig. 1 Marketed drugs having benzimidazole moiety

the benzimidazoles might be considered as auxiliary isosters of nucleotides having attached heterocyclic cores in their structures, cooperate effortlessly with biopolymers and have potential action for chemotherapeutic applications [6]. The benzimidazole moiety itself is an urgent pharmacophore in present day and has been used as privileged scaffolds to synthesize selective drugs of interest in numerous therapeutic areas including HIV-RT inhibitor [7], anticancer [8], antimicrobial [9], antihistamine [10], antihelmintic [11], antioxidant [12], antihypertensive [13], antiviral [14], anticoagulant [15] and antiulcer activity [16]. The marketed drugs having benzimidazole moiety (Fig. 1) i.e. (i) nocodazole, (ii) bendamustine, (iii) veliparib, (iv) glasdegib, (v) crenolanib, (vi) abemaciclib, (vii) liarozole, (viii) pracinostat. Malignancy is a gathering of various dangerous ailments described by uncontrolled development of cells, prompting attack of encompassing tissue and regularly spreading to different parts of the body [17]. Development of resistance and toxicity to normal rapidly growing cells are the major limitations of existing anticancer drugs, also majority of the drugs in the market that are not specific [8].

\section{Benzimidazole derivatives as antiproliferative agents}

Abonia et al. synthesized new derivatives of 1,2,5-trisubstituted benzimidazole and screened for their antiproliferative activity against the 60 human cancer cell lines (leukemia, melanoma, lung, colon, brain, ovary, breast and kidney carcinoma etc.) using
SRB protein assay to estimate cell growth. Among the synthesized compounds, compounds $\mathbf{1 a}$ and $\mathbf{1 b}$ (Fig. 2) displayed the utmost potency towards lung, melanoma and leukemia cancer cell lines $\left(\mathrm{GI}_{50}\right.$ values $1.15-$ $7.33 \mu \mathrm{M}$ and $0.167-7.59 \mu \mathrm{M})$, respectively and $\mathrm{LC}_{50}$ values more than $100 \mu \mathrm{M}$ [6].

Azam et al. developed a new series of 2-substituted benzimidazoles and screened for its cytotoxicity against selected human tumor cell lines: leukemia (THP-1), MCF-7, PC-3 and adenocarcinomic alveolar basal epithelial cell line (A-549) by trypan blue exclusion method. Among the synthesized compound, 2a exhibited promising activity against the tested cancer cell lines (Tables 1 and 2, Fig. 2) [18].

Coban et al. synthesized a new series of $1 \mathrm{H}$-benzimidazole compounds and screened for its cytostatic studies using HeLa, MCF7 and A431 cancer cell lines by MTT assay. Compound 3a exhibited the most profound cytotoxicity and comparable to standard drug (Table 3, Fig. 2) [19].

Demirayak et al. reported a series of pyrazino[1,2a]benzimidazole derivatives and evaluated for its in vitro anticancer activity against 60 human malignant cell lines: leukaemia (L), melanoma (M), NSCLC, $\mathrm{CC}, \mathrm{CNSC}, \mathrm{OC}, \mathrm{RC}, \mathrm{PC}$ and $\mathrm{BC}$ by SRB protein assay. Among the synthesized compounds, compound $4 \mathbf{a}$ was found to be most active anticancer agent and comparable to standard drugs (Table 4, Fig. 2) [20]. 
<smiles>COC(=O)c1ccc2c(c1)nc(-c1ccc(Cl)cc1)n2-c1cc(C(C)(C)C)[nH]n1</smiles>

$1 a$<smiles></smiles>

$3 a$<smiles>O=C(O)c1ccc2[nH]c(C[n+]3ccccc3)nc2c1</smiles>

$6 a$

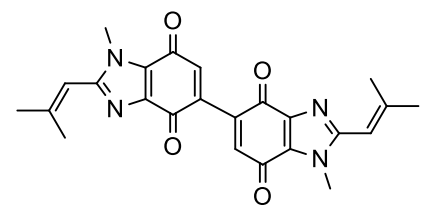

$8 \mathbf{a}$<smiles>CCN(CC)c1ccc(/C=N/c2nc3ccc(C#N)cc3[nH]2)c(O)c1</smiles>

11a<smiles>Cn1ccc2c1ccc1nc3ccccc3n12</smiles>

12b<smiles></smiles>

$1 \mathrm{~b}$

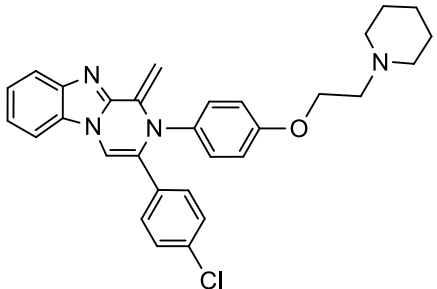

4a<smiles></smiles>

6b<smiles>COC(=O)c1ccc2c(c1)nc(-c1ccc(F)c([N+](=O)[O-])c1)n2CCc1ccc(OC)cc1</smiles>

9a<smiles>CCN(CC)c1ccc(/C=N/c2nc3ccc(C)cc3[nH]2)c(O)c1</smiles>

11b<smiles>Nc1cc(Br)c(-c2nnc(CCC(=O)c3nc4ccccc4[nH]3)o2)c(Br)c1</smiles>

$13 a$<smiles>Brc1ccc(-c2nc3ccccc3[nH]2)cc1</smiles>

2a<smiles>Oc1ccc2c(c1)nc(-c1ccccc1)n2Cc1ccc(OCCN2CCCCC2)cc1</smiles>

$5 a$<smiles>CC1=CC2=C(N)c3ccccc3N(Cc3nc4ccccc4[nH]3)C2=CC1</smiles>

$7 a$<smiles>COC(=O)Nc1nc2cc([Se]c3c[nH]c4ccccc34)ccc2[nH]1</smiles>

$10 a$<smiles>Cn1cccc1/C=C(\C#N)c1nc2ccccc2[nH]1</smiles>

12a

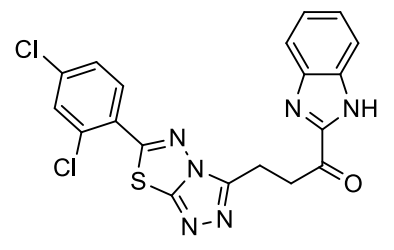

$14 a$

Fig. 2 Molecular structures of compounds (1a-1b, 2a, 3a, 4a, 5a, 6a-6b, 7a, 8a, 9a, 10a, 11a-11b, 12a-12b, 13a and 14a) 
Table 1 Percentage growth inhibition of compound 2a

\begin{tabular}{lccccc}
\hline Compound & Conc. $(\boldsymbol{\mu M})$ & \multicolumn{5}{l}{ Cancer cell lines } \\
\cline { 3 - 6 } & & \multicolumn{5}{l}{ \% Growth inhibition } \\
\cline { 3 - 6 } & & MCF-7 & THP-1 & PC-3 & A-549 \\
\hline 2a & 10 & 36 & 39 & 42 & 30 \\
& 50 & 93 & 68 & 60 & 70 \\
& 100 & 96 & 71 & 81 & 89 \\
Adriamycin & 1 & 72 & - & - & - \\
Paclitaxel & 1 & - & - & - & 65 \\
Mitomycin & 1 & - & - & 61 & - \\
5-FU & 20 & - & 67 & - & - \\
\hline
\end{tabular}

Table 2 Anticancer screening results of compound 2a

\begin{tabular}{lllll}
\hline Compound & \multicolumn{4}{l}{ Cancer cell lines $\left(\mathrm{IC}_{\mathbf{5 0}}=\mu \mathrm{M}\right)$} \\
\cline { 2 - 5 } & MCF-7 & THP-1 & PC-3 & A-549 \\
\hline 2a & $35 \pm 2$ & $48 \pm 2$ & $46 \pm 1$ & $43 \pm 2$ \\
\hline
\end{tabular}

Table 3 Anticancer screening results of compound $3 a$

\begin{tabular}{llll}
\hline Compound & \multicolumn{4}{l}{ Cancer cell lines $\left(\mathrm{IC}_{\mathbf{5 0}}=\boldsymbol{\mu M}\right)$} \\
\cline { 2 - 4 } & A431 & HeLa & MCF7 \\
\hline 3a & 6.16 & 6.04 & 6.94 \\
Doxorubicin & 0.19 & 0.16 & 0.31 \\
\hline
\end{tabular}

Dettmann et al. developed a new series of 2-phenyl1-[4-(2-piperidin-1-yl-ethoxy) benzyl]- $1 H$-benzimidazole derivatives and evaluated for its cytotoxicity against human MCF-7 and MDA-MB-231 breast cancer cell lines. Among the synthesized derivatives, compound $\mathbf{5 a}$ displayed highest cytostatic effects $(\mathrm{T} / \mathrm{Ccorr} \approx 0 \%)$ and comparable to reference $(\mathrm{T} / \mathrm{Ccorr}=0-20 \%)$ effects at a concentration of $5 \mu \mathrm{M}$ than the standard drug cisplatin (Fig. 2) [21].

Galal et al. synthesized a new class of benzimidazole5-carboxylic acid derivatives and evaluated for its anticancer activity (growth inhibitory) against 21 human tumor cell lines (seven colon, eight lung and six gastric) by SRB assay. Compounds $\mathbf{6 a}$ and $\mathbf{6 b}$ showed 10 times
Table 5 Anticancer activity (growth inhibitory) results of compounds (6a and $6 b$ )

\begin{tabular}{ll}
\hline Compounds & $\begin{array}{l}\mathrm{GI}_{\mathbf{5 0}}(\mathbf{5 0 \%} \text { cell } \\
\text { growth inhibition } \\
\text { in } \boldsymbol{\mu M})\end{array}$ \\
\hline $\mathbf{6 a}$ & 0.095 \\
$\mathbf{6 b}$ & 0.091 \\
Etoposide & 1.3 \\
Doxorubicin & 0.065 \\
SN-38 & 0.066 \\
Cisplatin & 3.9 \\
\hline
\end{tabular}

superior inhibitory result than etoposide as reference (Table 5, Fig. 2) [22].

Gao et al. synthesized a novel series of benzimidazole acridine derivatives and evaluated for its in vitro cytotoxicity toward human erythroleukaemia K562 and malignant hepatoma HepG-2 cells by MTT assay. From this series, compound $7 \mathbf{a}$ exhibited maximum cytotoxicity against both $\mathrm{K} 562\left(\mathrm{IC}_{50}=2.68 \mu \mathrm{M}\right)$ and HepG-2 $\left(\mathrm{IC}_{50}=8.11 \mu \mathrm{M}\right)$ cells as compared to standard drugs colchicin $\left(\mathrm{IC}_{50}=1.80 \mu \mathrm{M}\right.$ for HepG-2) and imatinib $\left(\mathrm{IC}_{50}=0.47 \mu \mathrm{M}\right.$ for K562) (Table 6, Fig. 2) [23].

Gellis et al. synthesized novel benzimidazole-4,7-dione molecules and evaluated for their cytotoxicity on colorectal, breast and lung cancer cell lines using MTT assay. Among the synthesized compounds, compound 8a showed tremendous activity $\left(\mathrm{IC}_{50} \pm 3 \mu \mathrm{M}\right)$ and comparable to mitomycin $C$ with $\mathrm{IC}_{50} \pm 0.9 \mu \mathrm{M}$ (Fig. 2) [24].

Gowda et al. reported a new series of benzimidazole-5-carboxylic acid derivatives and evaluated for its anticancer activity on K562 and CEM cancer cell using DMSO as vehicle control by the trypan blue and MTT assays. In this series, compound 9a exhibited maximum apoptosis in leukemic cell accompanying an $\mathrm{IC}_{50}=3 \mu \mathrm{M}$ (Fig. 2) [25].

Guan et al. developed a new class of benzimidazole carbamates with indole moiety and accessed for its antiproliferative activity against three tumor cell lines (SGC-7901, A-549 and HT-1080) using MTT assay. In this series, compound 10a displayed the highest antiproliferative activity towards selected cancer cell lines (Table 7, Fig. 2) [26].

Table 4 Antiproliferative activity of compound 4a

\begin{tabular}{lllllllllll}
\hline Compound & \multicolumn{2}{l}{ Cancer cell lines $\left(\log \mathbf{G I}_{\mathbf{5 0}}\right.$ ) } \\
\cline { 2 - 10 } & $\mathbf{L}$ & NSCLC & CC & CNSC & M & OC & RC & PC & BC & MG-MID \\
\hline $\mathbf{X}$ & -5.48 & -5.17 & -5.11 & -5.12 & -5.08 & -5.18 & -4.99 & -4.49 & -4.79 & -5.09 \\
$\mathbf{Y}$ & -6.39 & -6.20 & -6.14 & -6.18 & -6.08 & -6.45 & -6.17 & -6.41 & -6.05 & -6.20 \\
$\mathbf{4 a}$ & -6.40 & -4.40 & -4.00 & -4.92 & -4.47 & -4.00 & -4.00 & -4.00 & -4.62 & -4.63 \\
\hline
\end{tabular}

X: Melphalan; Y: cis-diaminedichloroplatinum 
Table 6 Anticancer activity results of compound 7a

\begin{tabular}{lll}
\hline Compound & Cancer cell lines & IC $_{\mathbf{5 0}}(\boldsymbol{\mu M})$ \\
\hline \multirow{3}{*}{ 7a } & U251 & 2.39 \\
& A375 & 3.20 \\
& A172 & 2.86 \\
& Hela & 2.76 \\
& CNE-2 & 2.62 \\
& U118-MG & 1.98
\end{tabular}

Table 7 Anticancer screening results of compound 10a

\begin{tabular}{llll}
\hline Compound & \multicolumn{4}{l}{ Cancer cell lines $\left(\mathrm{IC}_{\mathbf{5 0}}=\mu \mathrm{M}\right)$} \\
\cline { 2 - 4 } & SGC-7901 & A-549 & HT-1080 \\
\hline 10a & $0.098 \pm 0.002$ & $0.15 \pm 0.05$ & $0.13 \pm 0.07$ \\
Nocodazole & $0.080 \pm 0.01$ & $0.12 \pm 0.03$ & $0.14 \pm 0.005$ \\
\hline
\end{tabular}

Table 8 Anticancer screening results of compounds (11a and $11 \mathrm{~b})$

\begin{tabular}{llllll}
\hline Compounds & \multicolumn{6}{l}{ Cancer cell lines $\left(\mathbf{I C}_{\mathbf{5 0}}=\boldsymbol{\mu M}\right)$} \\
\cline { 2 - 6 } & HeLa & MCF-7 & SW620 & MiaPaCa-2 & W138 \\
\hline $\mathbf{1 1 a}$ & 4.73 & 9.23 & 49.15 & 27.92 & 0.96 \\
$\mathbf{1 1 b}$ & 3.24 & 15.27 & 52.04 & 22.24 & 1.67 \\
\hline
\end{tabular}

Hranjec et al. synthesized new benzimidazole substituted Schiff bases and evaluated for their in vitro antiproliferative activity toward human cancer cell lines i.e. HeLa (cervical carcinoma), SW620 (colorectal adenocarcinoma, metastatic), MiaPaCa-2 (pancreatic carcinoma), MCF-7 (breast epithelial adenocarcinoma, metastatic) and WI38 (normal diploid human fibroblasts) by MTT assay. From the synthesized compounds, compounds 11a and 11b displayed highest antiproliferative activity (Table 8, Fig. 2) [27].

Hranjec et al. synthesized a new series of novel benzimidazole derivatives and evaluated for its antiproliferative activity on five different cancer cell lines: HeLa, pancreatic (MiaPaCa-2), colon (SW 620), MCF-7 and lung ( $\mathrm{H} 460)$ cell lines by MTT assay. Among them, compounds 12a and 12b displayed the highest activity on tested cell lines and demonstrated an exceptional selectivity for HeLa cells (Table 9, Fig. 2) [28].

Husain et al. synthesized a new class of benzimidazole having oxadiazole and triazolo-thiadiazoles moiety and evaluated for its in vitro anticancer potential at concentration $(10 \mu \mathrm{M})$ against NCI 60 cell lines by five dose assay. Compound 13a displayed considerable growth reticence with $\mathrm{GI}_{50}$ efficacy from 0.49 to
Table 9 Anticancer activity results of compounds (12a and 12b)

\begin{tabular}{lccccc}
\hline Compounds & \multicolumn{6}{l}{ Cancer cell lines $\left(\mathrm{IC}_{\mathbf{5 0}}=\boldsymbol{\mu M}\right)$} \\
\cline { 2 - 6 } & HeLa & MiaPaCa-2 & SW 620 & MCF-7 & H 460 \\
\hline 12a & $0.8 \pm 0.4$ & $4 \pm 2$ & $30 \pm 5$ & $13 \pm 3$ & $26 \pm 13$ \\
12b & $0.7 \pm 0.2$ & $4 \pm 2$ & $25 \pm 4$ & $11 \pm 1$ & $22 \pm 2$ \\
Cisplatin & $3 \pm 0.6$ & $4 \pm 3$ & $4 \pm 1$ & $12 \pm 6$ & $0.3 \pm 0.04$ \\
Doxorubicin & $0.04 \pm 0.009$ & $0.01 \pm 0.01$ & $0.02 \pm 0.01$ & $0.04 \pm 0.01$ & Not tested \\
\hline
\end{tabular}

48.0 $\mu \mathrm{M}$ especially in lung carcinoma cell HOP-92 $\left(\mathrm{GI}_{50}\right.$ 0.49, TGI 19.9, $\mathrm{LC}_{50}>100$ and $\log _{10} \mathrm{GI}_{50}-6.30$, $\log _{10}$ TGI - 4.70, $\log _{10} \mathrm{LC}_{50}>-4.00$ ) (Fig. 2) [29].

Husain et al. synthesized benzimidazole derivatives associated with triazolo-thiadiazole and triazolo-thiadiazine nucleus and screened for their in vitro anticancer potential at only concentration $\left(10^{-5} \mathrm{M}\right)$ toward NCI 60 cell lines by five dose assay. Among the synthesized compounds, compound 14a (Fig. 2) exhibited excellent results against 60 cell panel (MG-MID -6.07 , -5.51 and -4.85 value of $\log _{10} \mathrm{GI}_{50}, \log _{10}$ TGI and $\log _{10} \mathrm{LC}_{50}$, respectively) [30].

Kamal et al. synthesized novel terphenyl benzimidazole derivatives and screened for their antitumor potency in tumor cells i.e. oral, lung, ovarian, cervix, colon, breast and prostate cells by SRB method. Among the synthesized compounds, compounds $\mathbf{1 5 a}$ and $\mathbf{1 5} \mathbf{b}$ showed significant anticancer potency with $\mathrm{GI}_{50}$ values vary from $<0.1$ to $2.11 \mu \mathrm{M}$, whereas the positive control reference adriamycin demonstrated the $\mathrm{GI}_{50}$ value from 0.1 to $7.25 \mu \mathrm{M}$ (Fig. 3) [31].

Kamal et al. synthesized novel 2-aryl 1,2,4-oxadiazolo-benzimidazole compounds and evaluated for their in vitro anticancer screening against 60 tumor cell lines by SRB method. In this series, compounds $\mathbf{1 6 a}$ and 16b displayed significant cytoxicity against the majority of tumor cells with $\mathrm{GI}_{50}$ range from 0.79 to $28.2 \mu \mathrm{M}$ (Fig. 3) [32].

Lukevics et al. developed novel trimethylsilylpropyl substituted benzimidazole derivatives and screened for their anticancer activity on mouse hepatoma (MG22A), human fibrosarcoma (HT-1080), mouse melanoma (B16), mouse neuroblastoma (Neuro 2A) and normal mouse fibroblast cells by MTT assay. In this series, compounds, $17 \mathbf{a}$ and $\mathbf{1 7} \mathbf{b}$ showed significant activity in mouse melanoma (B16) having $\mathrm{TD}_{50}$ from 0.001 to $0.008 \mu \mathrm{g} / \mathrm{mL}$. In vivo screening of compound 17a showed high anticancer activity toward sarcoma S- 180 by $62 \%$ (Fig. 3) [33].

El-Nassan, synthesized a new series of benzimidazole derivatives and demonstrated for its in vitro anticancer activity on MCF7 by SRB assay. Among the synthesized 
<smiles>COc1cc(-c2ccc(-c3ccc(-c4nc5c(O)cccc5[nH]4)cc3)cc2)cc(OC)c1OC</smiles>

$15 \mathbf{a}$<smiles>COc1cc(-c2nc(-c3ccc(-c4nc5cc(F)ccc5[nH]4)cc3)no2)cc(OC)c1OC</smiles>

$16 a$<smiles>C[Si](C)(C)CCCn1cnc2ccccc21</smiles>

$17 \mathbf{a}$<smiles>O=C1OC2C=C(NCCO)C=CC2C=C1c1nc2ccccc2[nH]1</smiles>

$19 a$<smiles>C=CCn1c(C)nc2ccc(Nc3nc(Nc4ccc(F)cc4)nc4ccccc34)cc21</smiles>

20c<smiles>COc1ccc(C=O)c(-c2ccc(OCc3nc4ccccc4[nH]3)c(C)c2)c1</smiles>

22b<smiles>C[Si](C)(C)CCCn1cnc2ccccc21</smiles>

$17 b$<smiles>COc1cc(-c2ccc(-c3ccc(-c4nc5cc(C)ccc5[nH]4)cc3)cc2)cc(OC)c1OC</smiles>

$15 b$<smiles>COc1ccc2[nH]c(-c3ccc(-c4noc(-c5ccc(C)cc5)n4)cc3)nc2c1</smiles>

$16 \mathrm{~b}$<smiles>Clc1ccccc1C1NNCc2nc3ccccc3n21</smiles>

$18 \mathbf{a}$<smiles>C=CCn1c(C)nc2ccc(Nc3nc(Nc4ccc5nc(C)n(CC=C)c5c4)c4ccccc4n3)cc21</smiles>

$20 a$<smiles>Cc1nc2cc(/N=C3\SCC(=O)N3C(=O)c3ccccc3)ccc2n1Cc1ccccc1</smiles>

$21 a$<smiles>O=C(CCc1nnc(-c2ccc(Cl)cc2Cl)o1)c1nc2ccccc2[nH]1</smiles>

$23 a$

Fig. 3 Molecular structures of compounds (15a-15b, 16a-16b, 17a-17b, 18a, 19a, 20a-20c, 21a, 22a-22b and 23a)

derivatives, compound 18a $\left(\mathrm{IC}_{50}=0.0390 \mu \mathrm{M}\right)$ exhibited promising antitumor activity (Fig. 3) [34].

Paul et al. synthesized novel coumarin-benzimidazole conjugates and tested for their in vitro anticancer potency on 60 cancer cell lines by SRB assay. In this series, compound 19a was found to be most active agent against leukemia, breast, colon, prostate (PC-3) and melanoma (LOX IMVI) cancer cell lines, respectively and comparable to the standard drug (5-FU) (Table 10, Fig. 3) [35].

Paul et al. designed and synthesized novel quinazoline and benzimidazole conjugates and evaluated in vitro for 


\begin{tabular}{|c|c|c|}
\hline Cancer cell lines & Compound 19a & 5-Fluorouracil \\
\hline \multicolumn{3}{|l|}{ Leukemia } \\
\hline $\mathrm{HL}-60$ (TB) & 80.51 & 47.9 \\
\hline CCRF-CEM & 72.52 & 57.1 \\
\hline K-562 & 57.34 & 42.3 \\
\hline MOLT-4 & 38.03 & 43.1 \\
\hline RPMI-8226 & 46.65 & 41.4 \\
\hline \multicolumn{3}{|l|}{ Breast tumor } \\
\hline $\mathrm{T}-47 \mathrm{D}$ & 70.68 & 56.7 \\
\hline MDA-MB231/ATCC & 58.91 & 78.1 \\
\hline MDA-MB-468 & 48.37 & Not tested \\
\hline BT-549 & 33.10 & 37.8 \\
\hline \multicolumn{3}{|l|}{ Colon tumor } \\
\hline HCT-116 & 62.25 & 17.8 \\
\hline HCT-15 & 72.67 & 26.5 \\
\hline $\begin{array}{l}\text { Melanoma cancer } \\
\text { LOX IMVI }\end{array}$ & 54.29 & 30.4 \\
\hline $\begin{array}{l}\text { Prostate cancer } \\
\text { PC-3 }\end{array}$ & 56.69 & 58.2 \\
\hline
\end{tabular}

Table 11 Antitumor activity results of compounds (20a20c)

\begin{tabular}{|c|c|c|}
\hline Compounds & Activity $(\mu \mathrm{M})$ & MG-MID \\
\hline \multirow[t]{3}{*}{$20 a$} & $\mathrm{Gl}_{50}$ & 1.64 \\
\hline & TGl & 3.28 \\
\hline & $\mathrm{LC}_{50}$ & 5.50 \\
\hline \multirow[t]{3}{*}{$20 \mathrm{~b}$} & $\mathrm{Gl}_{50}$ & 0.81 \\
\hline & TGl & 2.08 \\
\hline & $\mathrm{LC}_{50}$ & 4.47 \\
\hline \multirow[t]{3}{*}{$20 c$} & $\mathrm{Gl}_{50}$ & 4.52 \\
\hline & TGl & 15.9 \\
\hline & $\mathrm{LC}_{50}$ & 57.1 \\
\hline \multirow[t]{3}{*}{ Quinazoline analogue } & $\mathrm{Gl}_{50}$ & 16.9 \\
\hline & TGl & 40.5 \\
\hline & $\mathrm{LC}_{50}$ & $>100$ \\
\hline \multirow[t]{3}{*}{ Benzimidazole analogue } & $\mathrm{Gl}_{50}$ & 18.1 \\
\hline & TGl & 33.4 \\
\hline & $\mathrm{LC}_{50}$ & 56.7 \\
\hline
\end{tabular}

their antitumor activity on 60 human tumor cell lines at a dose of $10 \mu \mathrm{M}$. From this series, compounds 20a, 20b and 20c were found to be most active against selected cancer cell lines (Table 11, Fig. 3) [36].

Ramla et al. synthesized a novel series of benzimidazole derivatives and evaluated for its inhibitory activity against Burkitt's lymphoma by Epstein-Barr virus
Table 12 Anticancer activity results of compounds (24a24c)

\begin{tabular}{lllll}
\hline Compounds & \multicolumn{5}{l}{ Cancer cell lines $\left(\mathrm{IC}_{\mathbf{5 0}} \boldsymbol{\mu M}\right)$} \\
\cline { 2 - 5 } & A549 & MCF-7 & HeLa & HaCaT \\
\hline $\mathbf{2 4 a}$ & 1.81 & 0.83 & 1.76 & $>50$ \\
$\mathbf{2 4 b}$ & 1.13 & 0.95 & 1.57 & $>50$ \\
$\mathbf{2 4 c}$ & 1.34 & 1.17 & 1.63 & $>50$ \\
5-Fluorouracil & 2.13 & 2.36 & 4.6 & 15.26 \\
Nocodazole & 1.87 & 1.6 & 2.83 & 8.9 \\
\hline
\end{tabular}

activation test. In this series, compound 21a exhibited $12.3 \%$ inhibitory activity (Fig. 3) [37].

Ranganatha et al. synthesized new benzophenonebenzimidazole derivatives and evaluated for their in vivo tumor inhibition against EAC cells via three independent assays (trypan blue dye exclusion, MTT and LDH release assay) using DMSO as a vehicle control. Compounds, 22a and 22b exhibited the highest cytotoxic effect $\left(\mathrm{IC}_{50} \sim 10 \mu \mathrm{M}\right.$ and $\left.\sim 16 \mu \mathrm{M}\right)$ among the synthesized derivatives (Fig. 3) [38].

Rashid et al. synthesized benzimidazoles with oxadiazole nucleus and evaluated for their in vitro anticancer activity at a single dose $(10 \mu \mathrm{M})$ in NCI 60 cell line panel using SRB assay. In this series, compound 23a with $\mathrm{GI}_{50}$ values between 0.79 and $17.8 \mu \mathrm{M}$ showed significant anticancer activity against tested cell lines (Fig. 3) [17].

Reddy et al. synthesized novel pyrazole containing benzimidazole conjugates and screened for their anticancer activity (growth inhibition) against lung-A549, MCF-7, HeLa and human keratinocyte cells-HaCaT using MTT assay. Among the synthesized derivatives, compounds 24a, 24b and 24c exhibited effective anti-proliferative activity toward cancer tested cell lines (Table 12, Fig. 4) [39].

Refaat et al. synthesized a novel series of 2-substituted benzimidazole derivatives and evaluated in vitro for its anticancer potency against HEPG2, MCF7 and HCT116 cell lines by SRB assay using doxorubicin as reference. Among the synthesized compounds, compounds 25a and 25b showed the highest potency against HEPG2 while compounds, 25c, 25d and 25e showed promising activity against MCF7. Compounds, 25d and 25e showed moderate activity against HCT116 (Table 13, Fig. 4) [40].

Rewcastle et al. synthesized a series of benzimidazole analogs and evaluated for its enzyme activity against the $\mathrm{p} 110 \alpha, \beta$ and $\delta$ isoforms of PI3K using a lipid kinase assay and also assessed for their antitumor activity against two human cancer cells lines, NZOV9 (Y1021C mutation of $p 110 \alpha$ enzyme) and NZB5 (wild-type p110 $\alpha$ enzyme) using cell proliferation assay. From this 
<smiles>Brc1ccc2nc(-c3cn(-c4ccccc4)nc3-c3ccccc3)[nH]c2c1</smiles>

$24 a$<smiles>Nc1c(-c2nc3cc(C(=O)O)ccc3[nH]2)sc(=S)n1Cc1ccccc1</smiles>

$25 a$<smiles>N#C/C(=C1/SCC(=O)N1c1ccccc1)c1nc2cc(Cl)ccc2[nH]1</smiles>

25d<smiles>CC(C1=CC=CC1=CC1CCC1)N1C(S)N=C2C=CC=CC21</smiles>

$27 a$<smiles>C=CCn1c(C)nc2cc(Nc3nc(N4CCCC4)nc4[nH]cnc34)ccc21</smiles>

$30 a$<smiles>Fc1ccc(-c2nn(-c3ccccc3)cc2-c2nc3cc(F)ccc3[nH]2)cc1</smiles>

24b<smiles>N#C/C(=C\c1ccc(F)cc1)c1nc2cc(Cl)ccc2[nH]1</smiles>

$25 b$<smiles>COc1ccccc1C1=CSC(=C(C#N)c2nc3cc(C(=O)O)ccc3[nH]2)N1c1ccc(Br)cc1</smiles>

$25 \mathrm{e}$<smiles>O=[N+]([O-])c1ccc(-c2nnc(Cn3c(Cc4cccc5ccccc45)nc4ccccc43)o2)cc1</smiles>

28a<smiles>Clc1ccc(-c2nn(-c3ccccc3)cc2-c2nc3cc(Cl)ccc3[nH]2)cc1</smiles>

24c<smiles>N#CC(=C1CCCCC1)c1nc2cc(C(=O)O)ccc2[nH]1</smiles>

$25 c$<smiles>CN(C)CCCOc1cccc2c1nc(C(F)F)n2-c1nc(N2CCOCC2)nc(N2CCOCC2)n1</smiles>

$26 a$

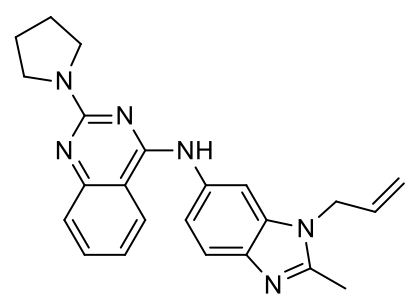

29a<smiles>CCOC(=O)c1ccc2c(c1)nc(-c1ccc(N(C)C)cc1)n2CCO</smiles>

31a<smiles>CCOC(=O)c1ccc2c(c1)nc(-c1ccc(N3CCCCC3)cc1)n2CCO</smiles>

31b<smiles>CCOC(=O)c1ccc2c(c1)nc(-c1ccc(C3OC=CO3)cc1)n2CCO</smiles>

31c

Fig. 4 Molecular structures of compounds (24a-24c, 25a-25e, 26a, 27a, 28a, 29a, 30a and 31a-31c) 
Table 13 Anticancer activity results (IC ${ }_{50}$ and $\left.I C_{90} \mu M\right)$ of compounds (25a-25e)

\begin{tabular}{llllll}
\hline Compounds & Cancer cell lines & IC $_{\mathbf{5 0}}$ & Doxorubicin & IC $_{\mathbf{9 0}}$ & Doxorubicin \\
\hline $\mathbf{2 5 a}$ & HEPG2 & $0.55 \pm 0.05$ & $0.59 \pm 0.03$ & $7.53 \pm 0.06$ & $6.82 \pm 0.06$ \\
$\mathbf{2 5 b}$ & HEPG2 & $0.55 \pm 0.03$ & $0.59 \pm 0.03$ & $7.62 \pm 0.09$ & $6.82 \pm 0.06$ \\
$\mathbf{2 5 c}$ & MCF7 & $2.15 \pm 0.04$ & $0.72 \pm 0.08$ & $11.70 \pm 0.17$ & $8.77 \pm 0.06$ \\
$\mathbf{2 5 d}$ & MCF7 & $2.83 \pm 0.03$ & $0.72 \pm 0.08$ & $12.63 \pm 0.09$ & $8.77 \pm 0.06$ \\
& HCT 116 & $3.72 \pm 0.03$ & $0.65 \pm 0.09$ & $12.02 \pm 0.07$ & $7.32 \pm 0.09$ \\
$\mathbf{2 5 e}$ & MCF7 & $2.85 \pm 0.15$ & $0.65 \pm 0.09$ & $13.25 \pm 0.13$ & $8.77 \pm 0.06$ \\
& HCT 116 & $3.75 \pm 0.16$ & $0.72 \pm 0.08$ & $12.05 \pm 0.06$ & $7.32 \pm 0.09$ \\
\hline
\end{tabular}

Table 14 Anticancer activity results (enzyme and cellular inhibition) of compound 26a

\begin{tabular}{llllll}
\hline Compound & $\begin{array}{l}\mathrm{p} 110 a \\
\mathrm{IC}_{\mathbf{5 0}}(\mathrm{nm})\end{array}$ & $\begin{array}{l}\mathrm{p} 110 \beta \\
\mathrm{IC}_{\mathbf{5 0}}(\mathrm{nm})\end{array}$ & $\begin{array}{l}\mathrm{p} 110 \delta \\
\mathrm{IC}_{\mathbf{5 0}}(\mathrm{nm})\end{array}$ & $\begin{array}{l}\text { NZB5 } \\
\mathrm{IC}_{\mathbf{5 0}}(\boldsymbol{\mu m})\end{array}$ & $\begin{array}{l}\text { NZOV9 } \\
\mathrm{IC}_{\mathbf{5 0}}(\boldsymbol{\mu m})\end{array}$ \\
\hline $\mathbf{2 6 a}$ & 11 & 7.3 & 4.5 & 0.17 & 0.04 \\
\hline
\end{tabular}

Table 15 Percentage growth inhibitory results (GI \%) of compound 29a

\begin{tabular}{lll}
\hline Cancer cell lines & Compound 29a & 5-Fluorouracil \\
\hline Leukemia & & \\
K-562 & 98.0 & 42.3 \\
MOLT-4 & 50.0 & 43.1 \\
RPMI-8226 & 45.0 & 41.4 \\
SR & 94.2 & 24.8 \\
Colon & & \\
HCC-2998 & 76.6 & Lethal \\
HCC-116 & 80.3 & 17.8 \\
HT29 & 94.3 & 27.1 \\
Melanoma & & \\
LOX IMVI & 97.5 & 30.4 \\
\hline
\end{tabular}

Table 16 Anticancer activity (\% cell inhibition) of compounds (31a-31c)

\begin{tabular}{lll}
\hline Compounds & \multicolumn{2}{l}{ Cancer cell lines } \\
\cline { 2 - 3 } & MCF-7 & MDA-MB-468 \\
\hline 31a & 49.63 & 46.33 \\
31b & 42.37 & 45.51 \\
31c & 62.43 & 42.30 \\
Cambinol & 38.26 & 22.09 \\
\hline
\end{tabular}

series, compound 26a exhibited best enzyme potency and also inhibiting tumor growth by $56.3 \pm 2.6 \%$ (Table 14, Fig. 4) [41].

Rodionov et al. synthesized novel ferrocenylalkyl 2-mercaptobenzimidazole derivatives and screened for
Table 17 Anticancer screening results of compound (32a32c)

\begin{tabular}{llll}
\hline Compounds & \multicolumn{3}{l}{ Cancer cell lines $\left(\mathrm{IC}_{\mathbf{5 0}} \boldsymbol{\mu M}\right)$} \\
\cline { 2 - 4 } & SKOV-3 & HeLa & BGC-823 \\
\hline 32a & 2.95 & $>50$ & $>50$ \\
32b & 38.60 & 7.1 & 16.4 \\
32c & 2.81 & 32.4 & 11.0 \\
Cisplatin & - & 1.6 & 1.3 \\
Taxol & 0.00134 & - & - \\
\hline
\end{tabular}

their in vivo antitumor activity against the murine solid tumor, carcinoma 755 (Ca755), transplanted in mice. Among the synthesized compounds, compound 27a showed $87 \%$ tumor growth inhibition on carcinoma 755 at the dose of $250.0 \mathrm{mg} / \mathrm{kg}$ day as compared to control cisplatin (Fig. 4) [42].

Salahuddin et al. synthesized a novel series of benzimidazole molecules and screened for its in vitro anticancer activity on leukemia, melanoma, lung, colon, CNS, ovarian, renal, prostate and breast cancer cell lines. From this series, compound 28a displayed promising activity against MDA-MB-468 (breast cancer) and SK-MEL-28 (melanoma) (GP $=36.23$ and 47.56, respectively) (Fig. 4) [43].

Sharma et al. synthesized new benzimidazole-quinazoline conjugates and monitor for their growth inhibitory activity on 60 tumor cell lines. Among them, compound 29a exhibited superior activity on leukemia, colon and melanoma cancer cell lines as compared to standard 5-fluorouracil (Table 15, Fig. 4) [44].

Sharma et al. synthesized novel purine-benzimidazole conjugates then screened for their anticancer activity against 60 human malignant cell lines by Aurora-A kinase assay. Among them, compound 30a exhibited 1.25 fold more activity with $\mathrm{GI}_{50}$ value of $18.12 \mu \mathrm{M}$ (MG-MID) than the reference 5-FU, $\mathrm{GI}_{50}=22.60 \mu \mathrm{M}$ (Fig. 4) [45]. 
<smiles>COC1=C(C)C(C)=CC(CSc2nc3ccc(-c4ccc5nc(SCC6C=C(C)C(OC)=C(C)N6)[nH]c5c4)cc3[nH]2)N1</smiles>

$32 \mathbf{a}$<smiles>C1=CC(CSc2nc3ccc(-c4ccc5nc(SCC6=CCNC=C6)[nH]c5c4)cc3[nH]2)=CCN1</smiles>

32c<smiles>CC(C)[C@H](NC(=S)NCc1ccccc1)c1nc2ccccc2[nH]1</smiles>

$35 \mathbf{a}$<smiles>O=C(CSc1nc2ccccc2n1C(=O)c1ccccc1)Nc1cccc([N+](=O)[O-])c1</smiles>

37b<smiles>C1=CNC(CSc2nc3ccc(-c4ccc5nc(SCC6C=CC=CN6)[nH]c5c4)cc3[nH]2)C=C1</smiles>

32b

33a

$34 a$<smiles>O=C(CSc1nc2ccccc2n1C(=O)c1ccccc1)Nc1ccccc1F</smiles>

$37 \mathbf{a}$

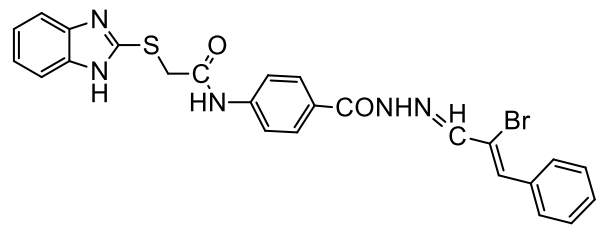

39a<smiles>O=C(CSc1nc2ccccc2[nH]1)N/N=C/c1ccc(O)c2ccccc12</smiles>

$36 \mathbf{a}$

$38 a$

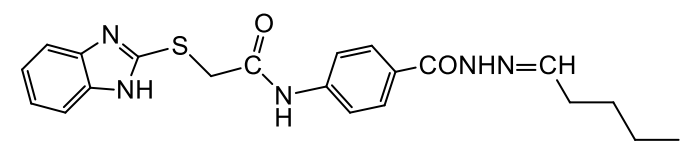<smiles>CC(C)CC=NNC(=O)c1cccc(NC(=O)CSc2nc3ccccc3[nH]2)c1</smiles>

$40 a$

Fig. 5 Molecular structures of compounds (32a-32c, 33a, 34a, 35a, 36a, 37a-37b, 38a, 39a-39b and 40a) 


\begin{tabular}{|c|c|c|c|c|}
\hline \multirow[t]{2}{*}{ Compound } & \multicolumn{3}{|c|}{$\begin{array}{l}\text { Cancer cell lines } \\
\left(\mathrm{GI}_{50} \mu \mathrm{M}\right)\end{array}$} & \multirow{2}{*}{$\begin{array}{l}\text { Inhibition } \\
\text { of tubulin } \\
\text { polymerization } \\
\left(\mathrm{IC}_{50} \mu \mathrm{M}\right)\end{array}$} \\
\hline & HepG2 & A549 & MCF-7 & \\
\hline $33 a$ & 3.8 & 2.4 & 5.1 & 1.5 \\
\hline CA-4 & 7.4 & 2.8 & 9.4 & 1.8 \\
\hline Colchicine & 10.5 & 4.4 & 13.5 & 2.62 \\
\hline
\end{tabular}

Yoon et al. synthesized a new class of benzimidazole derivatives and evaluated in vitro for its antiproliferative activity using human breast cancer MCF-7 and MDA-MB-468 cells by inner salt assay. From this series, compounds 31a, 31b and 31c showed good antiproliferative activity against MCF-7 and MDA-MB-468 cells (Table 16, Fig. 4) [46].

Yang et al. synthesized new symmetrical bis-benzimidazoles derivatives and evaluated in vitro for their cytotoxicity on HeLa, SKOV-3 and BGC-823 cell lines by MTT assay. In this series, compounds 32a, 32b and 32c displayed significant activity against tested cancer cell lines (Table 17, Fig. 5) [47].

Wang et al. synthesized new chain of benzene acyl2-(1-methylindol-3-yl)-benzimidazole derivatives and screened for its tubulin polymerization inhibitory activity and cytotoxicity against anthropic A549, HepG2 and MCF-7 tumor cell lines by MTT assay. Among the synthesized derivatives, compound 33a displayed excellent activity and comparable to colchicine and CA-4 as standards (Table 18, Fig. 5) [48].

Wang et al. reported novel benzimidazole-2-urea derivatives and tested for their antiproliferative activity against a group of human tumor cells using MTT assay. In this series, compound 34a exhibited the potent antiproliferative activity and compared to standard drugs (Table 19, Fig. 5) [49].

Madabhushi et al. synthesized some new benzimidazole functionalized chiral thioureas and screened for their cytotoxic activity against the human cancer cell lines (A549, MCF7, DU145 and HeLa) by MTT assay. From the synthesized compounds, compound 35a found
Table 20 Anticancer activity results $\mathrm{IC}_{50}(\mu \mathrm{M})$ of compound 35a

\begin{tabular}{lllcc}
\hline Compound & \multicolumn{4}{l}{ Cancer cell lines } \\
\cline { 2 - 5 } & A549 & MCF7 & DU145 & HeLa \\
\hline 35a & 5.2 & 9.8 & 12.3 & 11.1 \\
Doxorubicin & 0.8 & 0.7 & 0.8 & 0.6 \\
\hline
\end{tabular}

Table 21 Anticancer activity results of synthesized compound 36 a

\begin{tabular}{ll}
\hline Compound & $\begin{array}{l}\text { Cancer } \\
\text { cell line } \\
\left(\text { IC }_{50}=\mu M\right) \\
\text { MCF7 }\end{array}$ \\
\hline 36a & 0.0013 \\
5-FU & 0.0461 \\
Carboplatin & 0.2694
\end{tabular}

Table 22 Anticancer screening results of compounds (37a and 37b)

\begin{tabular}{lll}
\hline Compounds & \multicolumn{2}{l}{ Cancer cell lines $\left(\mathrm{IC}_{\mathbf{5 0}}=\boldsymbol{\mu M} / \mathrm{mL}\right)$} \\
\cline { 2 - 3 } & MCF7 & HCT116 \\
\hline 37a & 0.0047 & 0.0839 \\
37b & 0.0786 & 0.0058 \\
Tamoxifen & 0.0043 & - \\
5-FU & - & 0.0125 \\
\hline
\end{tabular}

to display significant activity against A549, DU145 and HeLa cell lines (Table 20, Fig. 5) [50].

Yadav et al. designed and synthesized a series of new benzimidazole derivatives and accessed for its cytotoxic potential against MCF7 (human breast adenocarcinoma cancer) cell line by SRB technique and compared to 5-FU and carboplatin standard drugs. In this series, compound 36a displayed the most potent anticancer activity (Table 21, Fig. 5) [51].

Yadav et al. synthesized some 2-(1-benzoyl$1 H$-benzo[d]imidazol-2-ylthio)- $N$-substituted acetamide

Table 19 Anticancer activity results $\left(\mathrm{IC}_{50} \mu \mathrm{M}\right)$ of compound $34 \mathrm{a}$

\begin{tabular}{|c|c|c|c|c|c|c|c|}
\hline \multirow[t]{2}{*}{ Compound } & \multicolumn{7}{|c|}{ Cancer cell lines } \\
\hline & $\mathrm{NCl}-\mathrm{H} 460$ & Colo205 & K562 & A431 & HepG2 & Hela & MDA-MB-435S \\
\hline $34 a$ & 0.040 & 0.050 & 0.006 & 0.026 & 1.774 & 0.452 & 0.052 \\
\hline Colchicine & 0.021 & 0.003 & 0.001 & 0.008 & 1.710 & 0.704 & 0.007 \\
\hline Taxol & 0.010 & 0.003 & 0.004 & 0.007 & 0.990 & 0.410 & 0.009 \\
\hline
\end{tabular}


Table 23 Anticancer screening results of compound 38a

\begin{tabular}{ll}
\hline Compound & $\begin{array}{l}\text { Cancer cell line } \\
\left(\mathrm{IC}_{\mathbf{5 0}}=\mu \mathrm{M} / \mathrm{mL}\right)\end{array}$ \\
& HCT116 \\
\hline $38 \mathrm{a}$ & 0.00005 \\
$5-\mathrm{FU}$ & 0.00615 \\
\hline
\end{tabular}

Table 24 Anticancer activity results of synthesized compounds (39a and 39b)

\begin{tabular}{ll}
\hline Compounds & $\begin{array}{l}\text { Cancer cell } \\
\text { line }\left(\mathrm{IC} \mathrm{C}_{50}=\mu \mathrm{g} /\right. \\
\mathrm{mL}) \\
\mathrm{HCT} 116\end{array}$ \\
\hline $39 \mathrm{a}$ & 8 \\
$39 \mathrm{~b}$ & 7 \\
$5-\mathrm{FU}$ & 2.63 \\
\hline
\end{tabular}

Table 25 Anticancer activity results of synthesized compound 40a

\begin{tabular}{ll}
\hline Compound & $\begin{array}{l}\text { Cancer cell } \\
\text { line }\left(\mathrm{IC} \mathrm{C}_{\mathbf{5}}=\boldsymbol{\mu g} /\right. \\
\mathrm{mL}) \\
\end{array}$ \\
$\mathrm{HCT1} 116$ \\
\hline $40 \mathrm{a}$ & 30 \\
$5-\mathrm{FU}$ & 0.85 \\
\hline
\end{tabular}

Table 26 Percentage inhibition results of tested compounds (41 a and 41b)

\begin{tabular}{llll}
\hline Compounds & \multicolumn{3}{l}{ Cancer cell lines } \\
\cline { 2 - 4 } & MCF-7 & HELA & A549 \\
\hline 41a & 95 & 54 & 77 \\
41b & 80 & 35 & 72 \\
Cisplatin & 60 & 35 & 60 \\
\hline
\end{tabular}

derivatives and evaluated for their anticancer activity against MCF7 and HCT116 cancer cell lines by SRB assay using tamoxifen and 5-FU as references. Among the synthesized compounds, compounds $37 \mathbf{a}$ and $37 \mathbf{b}$ emerged out as excellent anticancer agents (Table 22, Fig. 5) [52].

Yadav et al. synthesized a class of novel benzimidazole derivatives and screened for its antitumor potency towards HCT116 cancer cell line by SRB method and comparable to standard drug 5-FU. Compound 38a showed prominent antitumor activity (Table 23, Fig. 5) [53].
Tahlan et al. synthesized a series of new 2-mercaptobenzimidazole Schiff base derivatives and evaluated for its antitumor potency against HCT116 cancer cell line by SRB method using 5-FU as reference. In this series, compounds 39a and 39b showed significant antitumor activity towards tested cell line (Table 24 and Fig. 5) [8].

Tahlan et al. reported a class of novel benzimidazole azomethine derivatives and screened for its anticancer potency against HCT116 cancer cell line by SRB method using 5-FU as standard. Among the synthesized compounds, compound 40a was found to be most potent anticancer agent against selected cancer cell line (Table 25 and Fig. 5) [9].

Mohammed et al. synthesized a class of new substituted benzimidazoles and screened for its anticancer activity against breast adenocarcinoma MCF-7, lung carcinoma A549 and epithelioid cervix carcinoma HeLa using SRB colorimetric assay. Among the synthesized compounds, compounds 41a and 41b were found to be most active anticancer agents and comparable to the cisplatin (reference drug) (Table 26, Fig. 6) [54].

Aikman et al. developed some gold(III) pyridine-benzimidazole complexes and evaluated for their antitumor activity against human SKOV-3, A375, MCF-7 and A549 cancer cell lines by MTT assay using Auphen (stock solution $10 \mathrm{mM}$ in DMSO) as reference. Compounds 42a42c showed promising anticancer activity, particularly in the melanoma A375 cancer cell line (Table 27, Fig. 6) [55].

Onnis et al. synthesized a series of novel benzimidazolehydrazones and evaluated for its anticancer activity against murine leukemia (L1210), T-lymphoblastic leukemia (CEM), cervix carcinoma (HeLa) and pancreas carcinoma (Mia Paca-2) cell lines. In this series, compounds 43a and 43b inhibited the growth of all tested cell lines (Table 28, Fig. 6) [56].

Tahlan et al. designed and synthesized a series of substituted benzimidazole benzamide derivatives and screened for its anticancer potency against HCT116 cancer cell line by SRB method using 5-FU as standard. In this series, compound $\mathbf{4 4 a}$ and $\mathbf{4 4 b}$ were found to be most potent compounds against tested cell line (Table 29, Fig. 6) [57].

Tahlan et al. designed and synthesized some novel benzimidazole derivatives and accessed for their antiproliferative potential towards HCT116 cancer cell line by SRB method. Among the synthesized derivatives, compound 45a displayed the most potent anticancer activity (Table 30, Fig. 6) [58].

Wang et al. developed a class of novel substituted benzimidazole derivatives and evaluated its antiproliferative activity against MGC-803, MCF-7, HepG2 and MFC cells by MTT colorimetric assay. In this class, compound 46a 
<smiles>O=C(CNc1nc2ccccc2[nH]1)Nc1nc2ccccc2[nH]1</smiles>

$41 \mathrm{a}$<smiles></smiles>

42b<smiles>COc1ccc(/C=N/NC(=O)c2nc3ccccc3[nH]2)c(O)c1</smiles>

$43 a$<smiles>Cc1cccc(C)c1NC(=O)c1ccc(NC(=O)CSc2nc3ccccc3[nH]2)cc1</smiles>

$44 a$<smiles>COc1ccc(NC(=O)c2cccc(NC(=O)CSc3nc4ccccc4[nH]3)c2)cc1</smiles>

45a<smiles>O=C(Nc1nc2ccccc2[nH]1)C(=O)Nc1cccc2c1C(=O)c1ccccc1C2=O</smiles>

41b<smiles></smiles>

$42 a$<smiles></smiles>

42c<smiles>O=C(N/N=C/c1c(O)ccc2ccccc12)c1nc2ccccc2[nH]1</smiles>

43b<smiles>COc1ccc(NC(=O)c2ccc(NC(=O)CSc3nc4ccccc4[nH]3)cc2)cc1</smiles>

44b

Fig. 6 Molecular structures of compounds (41a-41b, 42a-42c, 43a-43b, 44a-44b, 45a, 46a and 47a)

Table 27 Anticancer activity results of synthesized compounds (42a-42c)

\begin{tabular}{lcccl}
\hline Compounds & \multicolumn{4}{l}{ Cancer cell lines $\left(\mathrm{EC}_{\mathbf{5 0}}(\boldsymbol{\mu M})\right)$} \\
\cline { 2 - 5 } & SKOV-3 & A375 & MCF-7 & A549 \\
\hline 42a & $17 \pm 7$ & $5 \pm 2$ & $12 \pm 1$ & $>50$ \\
42b & $33 \pm 5$ & $12 \pm 2$ & $29 \pm 8$ & $>50$ \\
42c & $41 \pm 13$ & $13 \pm 2$ & $17 \pm 3$ & $45 \pm 3$ \\
Auphen & $7.00 \pm 2.00$ & $1.7 \pm 0.3$ & $3.00 \pm 0.05$ & $1.07 \pm 0.09$ \\
\hline
\end{tabular}

showed remarkable anticancer activity as compared with standard drugs 5-FU and chrysin (Table 31, Fig. 6) [59].

El-Gohary et al. designed and synthesized a class of novel benzimidzole scaffolds and screened for its in vitro antiproliferative activity against three different cancer cell lines i.e. HepG2, HCT-116, MCF-7 and normal (W138) cell lines employing MTT assay. Among the synthesized compounds, compound 47a displayed significant antitumor activity and comparable to standard 5-FU (Table 32, Fig. 6) [60].

\section{Conclusion}

Benzimidazole is a promising category of bioactive heterocyclic compound that exhibit wide variety of biological activities because of its structural similarity with the naturally occurring nucleotides and also a focusable moiety in discovery of novel drug design in medicinal field. The present review summarizes the chemistry of various substituted benzimidazole derivatives with their antiproliferative significance towards the various 
Table 28 Anticancer screening results of compounds (43a and 43b)

\begin{tabular}{llrll}
\hline Compounds & \multicolumn{4}{l}{ Cancer cell lines $\left(\mathrm{IC}_{\mathbf{5 0}}=\boldsymbol{\mu M}\right)$} \\
\cline { 2 - 5 } & L1210 & \multicolumn{1}{c}{ CEM } & HeLa & Mia Paca-2 \\
\hline 43a & $1.6 \pm 0.9$ & $0.98 \pm 0.02$ & $4.0 \pm 0.4$ & $6.3 \pm 3.2$ \\
43b & $2.9 \pm 1.3$ & $1.0 \pm 0.01$ & $2.5 \pm 1.4$ & $7.9 \pm 0.3$ \\
\hline
\end{tabular}

Table 29 Anticancer activity results of synthesized compounds (44a and 44b)

\begin{tabular}{ll}
\hline Compounds & $\begin{array}{l}\text { Cancer } \\
\text { cell line } \\
\left(\mathrm{IC}_{\mathbf{5 0}}=\mu \mathrm{M}\right) \\
\text { HCT116 }\end{array}$ \\
\hline $\mathbf{4 4 a}$ & 5.85 \\
$\mathbf{4 4 b}$ & 4.53 \\
$5-\mathrm{FU}$ & 9.99 \\
\hline
\end{tabular}
Table 30 Anticancer activity results of synthesized
compound (45a)

\begin{tabular}{ll}
\hline Compound & $\begin{array}{l}\text { Cancer } \\
\text { cell line } \\
\left.\text { (IC }_{\mathbf{5 0}}=\mu \mathrm{M}\right)\end{array}$ \\
& HCT116 \\
\hline $45 \mathrm{a}$ & 4.12 \\
$5-\mathrm{FU}$ & 7.69 \\
\hline
\end{tabular}

Table 31 Anticancer activity results of synthesized compound (46a)

\begin{tabular}{lllll}
\hline Compound & \multicolumn{4}{l}{ Cancer cell lines $\left(\mathbf{I C}_{\mathbf{5 0}}=\boldsymbol{\mu M}\right)$} \\
\cline { 2 - 5 } & MGC-803 & MCF-7 & HepG2 & MFC \\
\hline 46a & $36.66 \pm 4.76$ & $73.21 \pm 2.41$ & $53.25 \pm 3.26$ & $25.72 \pm 3.95$ \\
5-FU & $74.39 \pm 2.03$ & $57.09 \pm 3.17$ & $63.37 \pm 2.52$ & $78.52 \pm 3.92$ \\
Chrysin & $>100$ & $>100$ & $73.29 \pm 3.81$ & $95.64 \pm 5.04$ \\
\hline
\end{tabular}

Table 32 In vitro anticancer activity results of synthesized compound (47a)

\begin{tabular}{lllll}
\hline Compound & \multicolumn{4}{l}{ Cancer cell lines $\left(\mathrm{IC}_{\mathbf{5 0}}=\mathrm{mM}\right)$} \\
\cline { 2 - 5 } & HepG2 & HCT-1 16 & MCF-7 & W138 \\
\hline 47a & 0.022 & 0.014 & 0.015 & 0.298 \\
5-FU & 0.061 & 0.041 & 0.0415 & 0.051 \\
\hline
\end{tabular}

cancer cell lines such as HCT116, MCF7, HepG2, HeLa, A549 and A431. Benzimidazole has established huge alertness in current time and is extremely significant heterocyclic pharmacophore in recent drug innovation and medicinal chemistry.

\section{Abbreviations}

SRB: sulforhodamide B; MTT: 3-(4,5-dimethylthiazol-2-yl)-2,5-diphenyl tetrazolium bromide; EAC: Ehrlich Ascites Carcinoma; LDH: lactate dehydrogenase; 5FU: 5-fluorouracil; $\mu$ M: micro mole; NSCLC: non-small-cell lung carcinoma; CC: colon cancer; CNSC: central nervous system cancer; OC: ovarian cancer; PC: prostate cancer; BC: breast cancer; RC: renal cancer; MCF7: breast adenocarcinoma 7; HCT116: human colorectal carcinoma; DMSO: dimethyl sulfoxide.

\section{Acknowledgements}

The authors are thankful to Head, Department of Pharmaceutical Sciences, Maharshi Dayanand University, Rohtak, for providing necessary facilities to carry out this research work.

\section{Authors' contributions}

BN, ST, SK and SK-have designed and prepared the review article. All authors read and approved the final manuscript.

\section{Funding}

Not applicable.

Availability of data and materials

Not applicable.

\section{Competing interests}

The authors declare that they have no competing interests.

Received: 1 January 2019 Accepted: 2 May 2019

Published online: 15 May 2019

References

1. Prajapat P, Kumawat M, Talesara GL, Kalal P, Agarwal S, Kapoor CS (2018) Benzimidazole scaffold as a versatile biophore in drug discovery: a review. Chem Biol Interfaces 8(1):1-10

2. Martins P, Jesus J, Santos S, Raposo LR, Roma-Rodrigues C, Baptista PV, Fernandes AR (2015) Heterocyclic anticancer compounds: recent advances and the paradigm shift towards the use of nanomedicine's tool box. Molecules 20:16852-16891

3. Khokra SL, Choudhary D (2011) Benzimidazole an important scaffold in drug discovery. Asian J Biochem Pharm Res 3(1):476-486

4. Hadole CD, Rajput JD, Bendre RS (2018) Concise on some biologically important 2-substituted benzimidazole derivatives. Org Chem Curr Res 7(3):1-9

5. Sivakumar R, Pradeepchandran R, Jayaveera KN, Kumarnallasivan $P$, Vijaianand PR, Venkatnarayanan R (2011) Benzimidazole: an attractive pharmacophore in medicinal chemistry. Int J Pharm Res 3(3):19-31

6. Abonia R, Cortes E, Insuasty B, Quiroga J, Nogueras M, Cobo J (2011) Synthesis of novel 1,2,5-trisubstituted benzimidazoles as potential antitumor agents. Eur J Med Chem 46:4062-4070

7. Ziolkowska NE, Michejda CJ, Bujacz GD (2009) Crystal structures of HIV-1 nonnucleoside reverse transcriptase inhibitors: $N$-benzyl-4-methyl-benzimidazoles. J Mol Struct 930:157-161

8. Tahlan S, Narasimhan B, Lim SM, Ramasamy K, Mani V, Shah SAA (2018) 2-Mercaptobenzimidazole Schiff bases: design, synthesis, antimicrobial studies and anticancer activity on HCT-116 cell line. Mini Rev Med Chem. https://doi.org/10.2174/1389557518666181009151008

9. Tahlan S, Narasimhan B, Lim SM, Ramasamy K, Mani V, Shah SAA (2018) Design, synthesis, SAR study, antimicrobial and anticancer evaluation of novel 2-mercaptobenzimidazole azomethine derivatives. Mini Rev Med Chem. https://doi.org/10.2174/1389557518666180903151849 
10. Lavrador-Erb K, Ravula SB, Yu J, Zamani-Kord S, Moree WJ, Petroski RE, Wen J, Malany S, Hoare SRJ, Madan A, Crowe PD, Beaton G (2010) The discovery and structure-activity relationships of 2-(piperidin-3-yl)$1 \mathrm{H}$-benzimidazoles as selective, CNS penetrating $\mathrm{H}_{1}$-antihistamines for insomnia. Bioorg Med Chem Lett 20:2916-2919

11. Hernandez-Covarrubias C, Vilchis-Reyes MA, Yepez-Mulia L, Sanchez-Diaz R, Navarrete-Vazquez G, Hernandez-Campos A, Castillo R, HernandezLuis F (2012) Exploring the interplay of physicochemical properties, membrane permeability and giardicidal activity of some benzimidazole derivatives. Eur J Med Chem 52:193-204

12. Kus C, Ayhan-Kilcigil G, Ozbey S, Kaynak FB, Kaya M, Coban T, Can-Eke B (2008) Synthesis and antioxidant properties of novel N-methyl-1,3,4-thiadiazol-2-amine and 4-methyl-2H-1,2,4-triazole-3(4H)-thione derivatives of benzimidazole class. Bioorg Med Chem 16:4294-4303

13. Zhang J, Wang J-L, Zhou Z-M, Li Z-H, Xue W-Z, Xua D, Li-P Hao, Han X-F, Fei F, Liu T, Liang A-H (2012) Design, synthesis and biological activity of 6-substituted carbamoyl benzimidazoles as new nonpeptidic angiotensin II AT, receptor antagonists. Bioorg Med Chem 20:4208-4216

14. Starcevic K, Kralj M, Ester K, Sabol I, Grce M, Pavelic K, Karminski-Zamola G (2007) Synthesis, antiviral and antitumor activity of 2-substituted-5-amidino-benzimidazoles. Bioorg Med Chem 15:4419-4426

15. Kuo H-L, Lien J-C, Chung C-H, Chang C-H, Lo S-C, Tsai I-C, Peng H-C, Kuo S-C, Huang T-F (2010) NP-184[2-(5-methyl-2-furyl) benzimidazole], a novel orally active antithrombotic agent with dual antiplatelet and anticoagulant activities. N-S Arch Pharmocol 381:495-505

16. Patil A, Ganguly S, Surana $S$ (2010) Synthesis and antiulcer activity of 2-[5-substituted-1-H-benzo(d) imidazol-2-yl sulfinyl]methyl-3-substituted quinazoline-4-(3H) ones. J Chem Sci 122(3):443-450

17. Rashid M, Husain A, Mishra R (2012) Synthesis of benzimidazoles bearing oxadiazole nucleus as anticancer agents. Eur J Med Chem 54:855-866

18. Azam M, Khan AA, Resayes SIA, Islam MS, Saxena AK, Dwivedi S, Musarrat J, Kruszynska AT, Kruszynski R (2009) Synthesis and characterization of 2-substituted benzimidazoles and their evaluation as anticancer agent. Spectrochim Acta A Mol Biomol Spectrosc 142:286-291

19. Coban G, Zencir S, Zupko I, Rethy B, Gunes HS, Topcu Z (2009) Synthesis and biological activity evaluation of $1 \mathrm{H}$-benzimidazoles via mammalian DNA topoisomerase I and cytostaticity assays. Eur J Med Chem 44:2280-2285

20. Demirayak S, Mohsen UA, Karaburun AC (2002) Synthesis and anticancer and anti-HIV testing of some pyrazino[1,2-a]benzimidazole derivatives. Eur J Med Chem 37:255-260

21. Dettmann S, Szymanowitz K, Wellner A, Schiedel A, Muller CE, Gust R (2010) 2-Phenyl-1-[4-(2-piperidine-1-yl-ethoxy)benzyl]-1H-benzimidazoles as ligands for the estrogen receptor: synthesis and pharmacological evaluation. Bioorg Med Chem 18:4905-4916

22. Galal SA, Hegab KH, Hashem AM, Youssef NS (2010) Synthesis and antitumor activity of novel benzimidazole-5-carboxylic acid derivatives and their transition metal complexes as topoisomerease II inhibitors. Eur J Med Chem 45:5685-5691

23. Gao C, Li B, Zhang B, Sun Q, Li L, Li X, Chen C, Tan C, Liu H, Jiang Y (2015) Synthesis and biological evaluation of benzimidazole acridine derivatives as potential DNA-binding and apoptosis-inducing agents. Bioorg Med Chem 23:1800-1807

24. Gellis A, Kovacic H, Boufatah N, Vanelle P (2008) Synthesis and cytotoxicity evaluation of some benzimidazole-4,7-diones as bioreductive anticancer agents. Eur J Med Chem 43:1858-1864

25. Gowda NRT, Kavitha CV, Chiruvella KK, Joy O, Rangappa KS, Raghavan SC (2009) Synthesis and biological evaluation of novel 1-(4-methoxyphenethyl)-1 H-benzimidazole-5-carboxylic acid derivatives and their precursors as antileukemic agents. Bioorg Med Chem Lett 19:4594-4600

26. Guan Q, Han C, Zuo D, Zhai M, Li Z, Zhang Q, Zhai Y, Jiang X, Bao K, Wu Y, Zhang W (2014) Synthesis and evaluation of benzimidazole carbamates bearing indole moieties for antiproliferative and antitubulin activities. Eur J Med Chem 87:306-315

27. Hranjec M, Starcevic K, Pavelic SK, Lucin P, Pavelic K, Zamola GK (2011) Synthesis, spectroscopic characterization and antiproliferative evaluation in vitro of novel Schiff bases related to benzimidazoles. Eur J Med Chem 46:2274-2279

28. Hranjec M, Pavlovic G, Marjanovic M, Kralj M, Zamola GK (2010) Benzimidazole derivatives related to 2,3-acrylonitriles, benzimidazo[1,2-a] quinolines and fluorenes: synthesis, antitumor evaluation in vitro and crystal structure determination. Eur J Med Chem 45:2405-2417

29. Husain A, Rashid M, Mishra R, Parveen S, Shin DS, Kumar D (2012) Benzimidazole bearing oxadiazole and triazolo-thiadiazoles nucleus: design and synthesis as anticancer agents. Bioorg Med Chem Lett 22:5438-5444

30. Husain A, Rashid M, Shaharyar M, Siddiqui AA, Mishra R (2013) Benzimidazole clubbed with triazolo-thiadiazoles and triazolo-thiadiazines: new anticancer agents. Eur J Med Chem 62:785-798

31. Kamal A, Reddy MK, Shaik TB, Rajender Srikanth YVV, Reddy VS, Kumar BG, Kalivendi SV (2012) Synthesis of terphenyl benzimidazoles as tubulin polymerization inhibitors. Eur J Med Chem 50:9-17

32. Kamal A, Reddy TS, Vishnuvardhan MVPS, Nimbarte VD, Rao AVS, Srinivasulu V, Shankaraiah N (2012) Synthesis of 2-aryl-1,2,4-oxadiazolo-benzimidazoles: tubulin polymerization inhibitors and apoptosis inducing agents Bioorg Med Chem 23:4608-4623

33. Lukevics E, Arsenyan P, Shestakova I, Domracheva I, Nesterova A, Pudova O (2001) Synthesis and antitumour activity of trimethylsilylpropyl substituted benzimidazoles. Eur J Med Chem 36:507-515

34. El-Nassan HB (2012) Synthesis, antitumor activity and SAR study of novel $[1,2,4]$ triazino[4,5- $a]$ benzimidazole derivatives. Eur J Med Chem 53:22-27

35. Paul K, Bindal S, Luxami V (2013) Synthesis of new conjugated coumarinbenzimidazole hybrids and their anticancer activity. Bioorg Med Chem Lett 23:3667-3672

36. Paul K, Sharma A, Luxami V (2013) Synthesis and in vitro antitumor evaluation of primary amine substituted quinazoline linked benzimidazole. Bioorg Med Chem Lett 24:624-629

37. Ramla MM, Omar MA, Tokuda H, El-Diwania HI (2007) Synthesis and inhibitory activity of new benzimidazole derivatives against Burkitt's lymphoma promotion. Bioorg Med Chem 15:6489-6496

38. Ranganatha VL, Avin BRV, Thirusangu P, Prashanth T, Prabhakar BT, Khanum SA (2013) Synthesis, angiopreventive activity and in vivo tumor inhibition of novel benzophenone-benzimidazole analogs. Life Sci 93:904-911

39. Reddy TS, Kulhari H, Reddy VG, Bansal V, Kamal A, Shukla R (2015) Design, synthesis and biological evaluation of 1,3-diphenyl-1H-pyrazole derivatives containing benzimidazole skeleton as potential anticancer and apoptosis inducing agents. Eur J Med Chem 101:790-805

40. Refaat HM (2015) Synthesis and anticancer activity of some novel 2-substituted benzimidazole derivatives. Eur J Med Chem 45:2949-2956

41. Rewcastle GW, Gamage SA, Flanagan JU, Kendall JD, Denny WA, Baguley BC, Buchanan CM, Chao M, Kestell P, Kolekar S, Lee WJ, Lill CL, Malik A, Singh R, Jamieson SMF, Shepherd PR (2015) Synthesis and biological evaluation of novel phosphatidylinositol 3-kinase inhibitors: solubilized 4-substituted benzimidazole analogs of 2-(difluoromethyl)-1-[4,6-di(4morpholinyl)-1,3,5-triazin-2-yl]-1H-benzimidazole (ZSTK474). Eur J Med Chem 64:137-147

42. Rodionov AN, Zherebker KY, Snegur LV, Korlyukov AA, Arhipov DE, Peregudov AS, Ilyin MM, Ilyin MM Jr, Nikitin OM, Morozova NB, Simene AA (2015) Synthesis, structure and enantiomeric resolution of ferrocenylalkyl mercaptoazoles. Antitumor activity in vivo. J Organomet Chem 783:83-91

43. Salahuddin, Shaharyar M, Mazumder A, d Ahsan MJ (2014) Synthesis, characterization and anticancer evaluation of 2-(naphthalen-1-ylmethyl/ naphthalen-2-yloxymethyl)-1-[5-(substituted phenyl)-[1, 3, 4]oxadiazol2-ylmethyl]-1H-benz imidazole. Arab J Chem 7:418-424

44. Sharma A, Luxami V, Paul K (2014) Synthesis, single crystal and antitumor activities of benzimidazole-quinazoline hybrids. Bioorg Med Chem Lett 23:3288-3294

45. Sharma A, Luxami V, Paul K (2015) Purine-benzimidazole hybrids: synthesis, single crystal determination and in vitro evaluation of antitumor activities. Eur J Med Chem 93:414-422

46. Yoon YK, Ali MA, Wei AC, Choon TS, Osman H, Parang K, Shirazi AN (2015) Synthesis and evaluation of novel benzimidazole derivatives as sirtuin inhibitors with antitumor activities. Bioorg Med Chem 22:703-710

47. Yang YH, Cheng MS, Wang QH, Nie H, Liao N, Wang J, Chen H (2009) Design, synthesis and anti-tumor evaluation of novel symmetrical bisbenzimidazoles. Eur J Med Chem 44:1808-1812

48. Wang YT, Qin YJ, Yang N, Zhang YL, Liu CH, Zhu HL (2015) Synthesis, biological evaluation and molecular docking studies of novel 1-benzene 
acyl-2-(1-methylindol-3-yl)-benzimidazole derivatives as potential tubulin polymerization inhibitors. Eur J Med Chem 99:125-137

49. Wang W, Kong D, Cheng H, Tan L, Zhang Z, Zhuang X, Long H, Zhou Y, Xu $Y$, Yang X, Ding K (2014) New benzimidazole-2-urea derivates as tubulin inhibitors. Bioorg Med Chem Lett 24:4250-4253

50. Madabhushi S, Mallu KKR, Vangipuram VS, Kurva S, Poornachandra Y, Kumar CG (2014) Synthesis of novel benzimidazole functionalized chiral thioureas and evaluation of their antibacterial and anticancer activities. Bioorg Med Chem Lett 24:4822-4825

51. Yadav S, Lim SM, Ramasamy K, Vasudevan M, Shah SAA, Mathur A, Narasimhan B (2018) Synthesis and evaluation of antimicrobial, antitubercular and anticancer activities of 2-(1-benzoyl-1 H-benzo[d]imidazol2-ylthio)-N-substitutedacetamides. Chem Cent J 12:66

52. Yadav S, Narasimhan B, Lim SM, Ramasamy K, Vasudevan M, Shah SAA, Selvaraj M (2017) Synthesis, characterization, biological evaluation and molecular docking studies of 2-(1H-benzo[d]imidazol-2-ylthio)N-(substituted-4-oxothiazolidin-3-yl)acetamides. Chem Cent J 11:137

53. Yadav S, Narasimhan B, Lim SM, Ramasamy K, Vasudevan M, Shah SAA Mathur A (2018) Synthesis and evaluation of antimicrobial, antitubercular and anticancer activities of benzimidazole derivatives. Egypt J Basic Appl Sci 5:100-109

54. Mohamed LW, Taher AT, Rady GS, Ali MM, Mahmoud AE (2018) Synthesis and biological evaluation of certain new benzimidazole derivatives as cytotoxic agents new cytotoxic benzimidazoles. Der Pharma Chemica 10(5):112-120

55. Aikman B, Wenzel MN, Mosca AF, de Almeida A, Klooster WT, Coles SJ, Soveral G, Casini A (2018) Gold(III)pyridine-benzimidazole complexes as aquaglyceroporin inhibitors and antiproliferative agents. Inorganics 6(123):1-16
56. Onnis V, Demurtas M, Deplano A, Balboni G, Baldisserotto A, Manfredini S, Pacifico S, Liekens S, Balzarini J (2016) Design, synthesis and evaluation of antiproliferative activity of new benzimidazolehydrazones. Molecules 21(579):1-9

57. Tahlan S, Ramasamy K, Lim SM, Shah SAA, Mani V, Narasimhan B (2019) 4-(2-(1H-Benzo[d]imidazol-2-ylthio)acetamido)- $\mathrm{N}$-(substituted phenyl) benzamides: design, synthesis and biological evaluation. BMC Chem 3(12): $1-16$

58. Tahlan S, Ramasamy K, Lim SM, Shah SAA, Mani V, Narasimhan B (2019) Design, synthesis and therapeutic potential of 3- $(2-(1 \mathrm{H}$-benzo[d]imidazol2-ylthio) acetamido)- $\mathrm{N}$-(substituted phenyl)benzamide analogues. Chem Cent J 12(139):1-12

59. Wang Z, Deng X, Xiong S, Xiong R, Liu J, Zou L, Lei X, Cao X, Xie Z, Chen Y, Liu Y, Zheng X, Tang G (2017) Design, synthesis and biological evaluation of chrysin benzimidazole derivatives as potential anticancer agents. Nat Prod Res. https://doi.org/10.1080/14786419.2017.1389940

60. El-Gohary NS, Shaaban MI (2017) Synthesis and biological evaluation of a new series of benzimidazole derivatives as antimicrobial, antiquorumsensing and antitumor agents. Eur J Med Chem. https://doi.org/10.1016/j. ejmech.2017.03.018

\section{Publisher's Note}

Springer Nature remains neutral with regard to jurisdictional claims in published maps and institutional affiliations.
Ready to submit your research? Choose BMC and benefit from:

- fast, convenient online submission

- thorough peer review by experienced researchers in your field

- rapid publication on acceptance

- support for research data, including large and complex data types

- gold Open Access which fosters wider collaboration and increased citations

- maximum visibility for your research: over $100 \mathrm{M}$ website views per year

At BMC, research is always in progress.

Learn more biomedcentral.com/submissions 